\title{
Valuation of nursing care in the preparation course for maternity and paternity
}

\section{Introduction}

Maternal health is included in the sustainable development objective 3: "health and wellness" charted in the UN conference in Rio de Janeiro in 2012., ${ }^{1,2}$ In Colombia prenatal care is regulated by Resolution 412 of 2000, in the Clinical Practice Guidelines "detection of alterations in pregnancy", updated in 2013 by the Ministry of Health and Social Protection of Colombia. ${ }^{3-5}$

Given the high birth rates in the country in the younger population, it is clear that there is no education in the family, in the community, and there is easy access to educational programs in schools and health institutions, by various cultural factors such as taboo on sexuality, family planning methods and gestation. ${ }^{6,7}$

For the conditions described previously in 2016 the Ministry of Health and Welfare announced the policy of comprehensive health care (PAIS), a law that gives rise to the Integral Model of Health Care (MIAS), which aims to generate comprehensiveness in health care and well-being of Colombians, for which coordination is required between all stakeholders in the health sector in order to carry out actions to regulate the determinants and risks that influence health and well-being population. ${ }^{8}$

For the implementation of this new model the Comprehensive Routes Health Care (RIAS), one of these is the comprehensive route health care 8 for perinatal maternal population were designed, in which actions are proposed to improve health conditions of the pregnant woman and her unborn child. ${ }^{8}$

On professional experience and literature has been observed that some pregnant women do not have adequate adherence to prenatal care programs, especially the preparation for parenthood, here are some factors that could explain this phenomenon are named :

1. Cultural barriers, as health professionals attending the mother, father and son trinomio not investigate the beliefs of the parents, so the approach is slightly customized..$^{9-11}$

2. Other barriers are times and limited availability by pregnant women and their partners to be engaged in other activities like being toiling. ${ }^{9-11}$

3. The authoritarian and rigid stance of the health professional who parents shown as an absolute connoisseur and does not allow a link or equal relationship with parents, and active participation by these. ${ }^{9-11}$

The process of gestation is a period of change for parents who are awaiting the new being; therefore becomes important care provided by health professionals especially nurses in order to propender for the welfare of the mother and the unborn child through the care given to this dyad and activities education that are provided during the prenatal period to prevent disturbances during pregnancy, childbirth, newborn care and to promote healthy habits during the prenatal and postpartum period. ${ }^{10-16}$

That is why the need to know and describe how valued the care
Volume 6 Issue 5 - 2019

\author{
Diana Marcela Martínez Vallejos,' Luz Mery \\ Hernández Molina ${ }^{2}$ \\ 'Department of Nursing, Sanitas University Foundation, \\ Colombia \\ ${ }^{2}$ Department of Nursing, National University of Colombia, \\ Colombia
}

Correspondence: Diana Marcela Martínez Vallejos, Nursing School, Sanitas University Foundation, Colombia,

Emaildimmartinezva@unal.edu.co

Received: October 16, 2018 | Published: October 25, 2019

provided by the nurse to pregnant women attending the preparation of motherhood and fatherhood in a private IPS in Bogotá through the application arises scale professional care scale derived from professional care (CPS) of Dr. Kristen Swanson Spanish version, $2011 .{ }^{17}$

\section{Materials and methods}

This study is descriptive quantitative approach, prospective took place in a private IPS in Bogotá during the second half of 2017. A sample of 331 pregnant women with a margin of error of $5 \%$ and confidence interval was calculated $95 \%$, simple random probability sampling was performed were included in older pregnant 15 -year study literate, between the second and third quarter had attended at least 2 of the 4 sessions of affiliates during the EPS linked to the IPS who applied the rating scale derived from professional care professional care scale (CPS) Dr. Kristen Swanson Spanish version, $2011 .{ }^{17}$

Researchers are girded with international ethical recommendations of CIOMS (Council for International Organizations of Medical Sciences), Resolution 008430 of 1993, Law 911 of 2004, the code of childhood and adolescence and ethical principles: truthfulness, fidelity, mutuality , beneficence, non-maleficence, autonomy and justice ${ }^{18}$ which was approved by the ethics committees of the Faculty of nursing National University of Colombia and the IPS Virrey Solis.

This instrument has two dimensions: healing competent and compassionate healer is valid global content of 0.893 and 0.907 Cronbach's alpha. ${ }^{17}$ The application of the scale was done in units of basic care institution providing health services in the sessions of preparation for parenthood, explanation and purpose of the study each gestante was made, it was verified its understanding, he surrendered in physical informed consent, which was completed by users and then I filled each format with the instrument.

The results of this research were analyzed taking into account the scores obtained after the application of the instrument scale professional care derived from the Caring Professional Scale (CPS) of Dr. Kristen Swanson, Spanish version 2011. ${ }^{17}$ 
Tabulation was performed on a spreadsheet Excel data obtained were then exported to SPSS version 24 and then analyzing the results and variables in order to test the hypothesis in this research was conducted.

\section{Results}

Participants were between 15 and 43 years old, average age was 25.8 years. Most pregnant women were between 21 and 27 years old, one can see that the number of pregnant women with extreme age was low, 7 pregnant were less than or equal to 16 years old and 30 greater than or equal to 35 .

As for the educational level: $3 \%$ had primary education, $42.9 \%$ had completed high school, $30.8 \%$ had completed a technical degree, $21.5 \%$ were professionals, while $1.8 \%$ had graduate, according to these statistics although the vast majority of pregnant women had a high school education and a large number of them had advanced levels of technical / university higher education if it could be inferred that pregnancy influences the opportunity to continue academic training as it has a major social impact because of the difficulty in simultaneously play the role of mother and child.

Referring to marital status variable $1.5 \%$ of pregnant women reported being separated, married $9.3 \%, 39.2 \% 49.8 \%$ while single living in union; While this may reflect an aspect that has much to do with religion and culture, could also be associated with educational level, occupation and socioeconomic status, according to data being presented could be concluded that pregnant women living in free union or who are single are among the lowest socioeconomic levels.

Faced with gynecological and obstetric history is important to note that most women who participated in this study were not planning a pregnancy or wanted at this point in their lives, yet all accept stated gestation. It may show that $75.2 \%$ of pregnant women did not plan their pregnancy, on the other hand $24.7 \%$ if they had planned.

As for the current pregnancy was evident maternal risk classification where $42.3 \%$ of pregnant women were classified as high risk while $57.7 \%$ low risk, according to the extreme age as maternal risk factor, it was shown that $83.3 \%$ of pregnant añosas and $71.4 \%$ of very young pregnant were taking a high-risk pregnancy; it is worth noting that took into account the risk classification were pregnant at the time of the instrument, since this information is subject to complications that can occur during pregnancy and may vary.

Participants were between weeks 14 and 39 of gestation with an average gestational age of 26.6; where the highest concentration of pregnant women was in week $23,24,25$ and $26.58 .3 \%$ of the participants were in the second quarter as $41.6 \%$ in the third trimester (Table 1).

Table I Instrument: profesional care scale derived from the Caring Professional Scale (CPS) of Dr. Kristen ${ }^{17}$

\begin{tabular}{|c|c|c|c|c|}
\hline Item & Never & $\begin{array}{l}\text { sometimes yes, } \\
\text { sometimes no }\end{array}$ & $\begin{array}{l}\text { most } \\
\text { times }\end{array}$ & Siempre \\
\hline \multicolumn{5}{|l|}{ Compassionate healer } \\
\hline Made her feel good? & 1 & 2 & 3 & 4 \\
\hline Showed a positive attitude with you and your pregnancy? & 1 & 2 & 3 & 4 \\
\hline I listen carefully to you? & 1 & 2 & 3 & 4 \\
\hline Are you allowed him to express his feelings? & I & 2 & 3 & 4 \\
\hline Are you showed interest in what happens to you? & I & 2 & 3 & 4 \\
\hline Have you understood your symptoms and concerns? & I & 2 & 3 & 4 \\
\hline $\begin{array}{l}\text { Did showed that he was prepared to do their job? } \\
\text { competent healer }\end{array}$ & 1 & 2 & 3 & 4 \\
\hline Is encouraged her to continue caring for your pregnancy? & I & 2 & 3 & 4 \\
\hline Was respectful to you? & I & 2 & 3 & 4 \\
\hline How will I provide help and collaboration? & 1 & 2 & 3 & 4 \\
\hline I realize correctly the course of preparation for parenthood? & I & 2 & 3 & 4 \\
\hline $\begin{array}{l}\text { What felt cared for during the course of preparation for } \\
\text { parenthood? }\end{array}$ & 1 & 2 & 3 & 4 \\
\hline Do I explain clearly the signs to follow? & I & 2 & 3 & 4 \\
\hline Was it nice to you? & 1 & 2 & 3 & 4 \\
\hline Is he treated as a person? & 1 & 2 & 3 & 4 \\
\hline
\end{tabular}

Vesga et al. $^{16}$ 


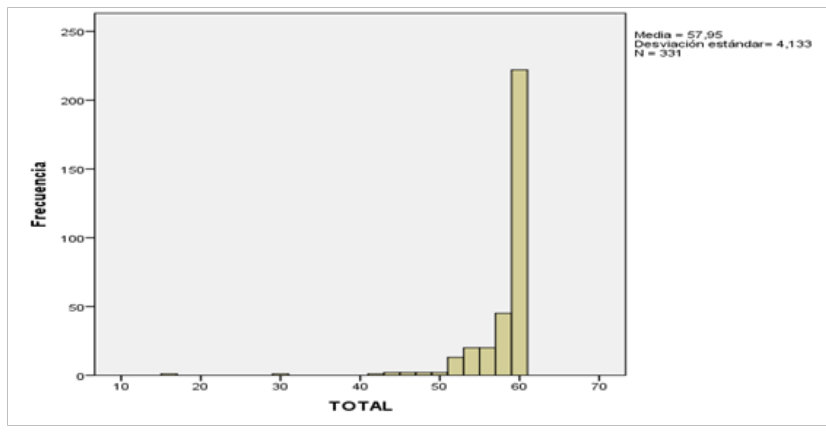

Figure I Total frequency scale.

Source: Data obtained by the researcher in this study: "Assessment of nursing care in the course of preparation for parenthood".

$57.7 \%$ of pregnant women gave the highest score in the dimension of compassionate healer while $74.3 \%$ gave the highest score in the dimension of competent healer. This fact makes evident that the skills of nursing professionals are notorious for the human component pregnant.

$0.3 \%$ of participants rated the care provided by nurses in the course of preparation for parenthood as deficient, as a regular $0.3 \%, 3.6 \%$ and $95.7 \%$ as good of pregnant women felt that the care provided by nurses in the course was excellent. Figure $194.2 \%$ of pregnant women with low risk pregnancies assessed care provided nursing preparation for parenthood as excellent figures 3.6 percentage points lower than those reported in participants who were enrolled with gestations highrisk.

$100 \%$ of pregnant women in extreme age and $95.2 \%$ of pregnant women between 17 and 34 evaluated the care provided by the nurse in the course as excellent.

$94.8 \%$ of pregnant women who were in the second trimester and $97.1 \%$ who were enrolled in their third trimester of pregnancy assessed as excellent the care received by nurses in the course of preparation for parenthood and paternity.

The data described allow us to see that there is a noticeable difference in the scores on the scale of professional care when comparing pregnant by chronological age, gestational age or risk classification.

\section{Discussion}

The findings on the social characteristics in this research agree in some respects with the perception study of nursing care in antenatal care Guzman, even if it comes from different regions of Colombia, as both it is reported that most pregnant cohabiting and have the secondary level. ${ }^{19}$

However differences in the ranges of chronological age where ages are reported from 18 to 35 in the study of Guzman found, whereas in the present investigation ages of pregnant women showed greater variability being between 15 and 43 years old. ${ }^{19}$

Regarding gynecological and obstetric history are also similarities between the two studies where more than half of the participants were primiparas. ${ }^{19}$

According to the score obtained in the two dimensions of the scale there are similarities compared to findings presented by Ortega in his studio, where the lowest score in the intervention group in the healing dimension competent was in item 11 he performed correctly control your pregnancy? (The preparation for parenthood for this study). ${ }^{20}$

In the dimension of the compassionate healer it demonstrated that the items with the lowest score in the same group were does he feel good? And it allowed him to express his feelings? while in the control group were allowed to have you express your feelings? And demonstrated interest in their symptoms and concerns?; in this investigation are presented some similarities with the study by Ortega opposite the score of the control group and intervention in item 4, while the control group with item $5 .{ }^{20}$ Although the population of both studies was different care settings valuation by pregnant women has similarities. ${ }^{20}$

As for the results obtained in this research, according to their score in the scale professional care derived from the Caring Professional Scale (CPS) of Dr. Kristen Swanson Spanish version, 2011, ${ }^{17}$ shows that the assessment of care offered by nurses to pregnant women who perform the preparation for parenthood excellent coincides with the findings in the study of Suarez and Bejarano, since in the latter after the interviews the researchers showed that pregnant perceived nursing care as a holistic which led them to conclude the preparation for parenthood it can be located in the vision of transformative nursing unitaria. $^{21}$

\section{Conclusion}

1. During preparation for parenthood is an encounter between expectant families and nursing professionals that allows them to express their feelings, thoughts and beliefs around the process of pregnancy, childbirth, postpartum and baby care newborn, acquire knowledge on the physical and emotional changes experienced in each quarter, helps reduce anxiety, to identify warning signs, to create new links and strengthen support networks, giving them the opportunity to acquire skills to care for these stages and It facilitates the transition from gestante to assume the role of parents ${ }^{22}$ family. ${ }^{23-25}$

2. Most pregnant women believe that nurses have the skills and abilities required for the performance of health care in the course of preparation for parenthood yet also believe that nurses should develop behaviors that enable them to establish a relationship of esteem and trust with care subjects. ${ }^{22}$

3. Is evidence that pregnant women who attend the preparatory course for maternity and paternity leave, made a positive assessment of care offered by nurses, considering this as an excellent and holistic care, however care should continue to improve, nurses must strive to find ways to establish a relationship with pregnant transcending and allow mutual learning. ${ }^{22-25}$

4. About $58 \%$ of pregnant women found that nurses who performed the preparation for parenthood had care skills that allowed them to establish a relationship of trust and affection.

5. Approximately $75 \%$ of pregnant nurses perceived that developed during preparation for parenthood had the skills and capabilities needed to provide care in this context.

6. No major differences in the assessment by pregnant when compared by the variables chronological age, gestational age or risk classification found. 
7. The context of the preparation for parenthood requires professional nursing skills of empathy, assertive communication, creativity and confidence in their knowledge and skills as well as respect and willingness to learn of expectant families. ${ }^{23-25}$

8. The vision of nursing that guides the work of the professional in the course of preparation for parenthood is integrative or mutual interaction interactive as this allows the nurse see in the gestating a holistic and interacting being, shows that reality is relative, multidimensional and dependent on the context in which it is immersed every pregnant woman, so care must be personalized and propender to meet congruently with the prospect of each subject needs. ${ }^{21}$

\section{Funding details}

Coordination for the Improvement of Higher Education Personnel - Capes.

\section{Acknowledgments}

None.

\section{Conflicts of interest}

The authors declare that there is no conflict of interest.

\section{References}

1. World Health Organization. Geneva: WHO; 2016.

2. Sustainable development objectives. NY: United Nations Development Program (UNDP); 2016.

3. Resolution 412. Guide 3: A Guide for the early detection of pregnancy disorders. Colombia: Ministry of Health; 2000.

4. Ministry of Health and Social Protection. Clinical Practice Guideline for prevention, early detection and treatment of complications of pregnancy, childbirth or postpartum. Bogota: Ministry of Health and Social Protection, Colciencias; 2013.

5. Amaya-Guío J, Diaz-Cruz LA, Cardona-Ospina A, et al. Clinical Guide for prevention and early detection of pregnancy disorders practice. Rev Colomb Obstet Ginecolde. 2013;64(2):245-288.

6. Moreno CM. Health Situation Analysis (ASIS). Colombia, Bogota: Ministry of Health and Social Protection; 2015.

7. Profamilia. National Demographic and Health Survey 2015; 2016.

8. Ministry of health and social protection. Policy of comprehensive health care "health system serving the people". 2016.

9. Acosta S, Bejarano NL, Castiblanco N, Castaneda LM, et al. Guide nursing care in prenatal care: Evidence Based Nursing (EBE). Bogotá: Mayor of Bogota, Ministry of Health; 2015.
10. Monsalve CA. Preparation for parenthood online guide. Bogota: Mayor of Bogota, Ministry of Health; 2016.

11. Angeles G, Rojas F, Maciel AC. Pregnant perception about prenatal care provided in the control. UAEMEX. 2015;9-18.

12. Vasconcelos MA, Fernández G, C Santos, Mendes V. The quality of nursing care in the prenatal period from the perspective of the pregnant woman. Rev Aquichán. 2014;14(2):196-206.

13. Hernandez Vasquez ML. Committed nursing care: engine satisfaction of pregnant women during antenatal care. Univ Salud. 2015;17:80-96.

14. Martínez JM, Contribution of maternal education to maternal and child health. Bibliographic review. Matronas Prof. 2016;15(4):137-141.

15. Muñoz L, Ruiz CH. Care of pregnant women. Ministry of Health and Social Protection. Protocols for nursing care and reprodructiva sexual health of women. 2014:192-210.

16. Barbosa ML. Narratives of pregnant women related to not take the decision to seek health services. Scientific threshold. 2006:47-61.

17. Vesga LM, Ruiz, CH. Validity and reliability of a scale of professional care in Spanish. Rev Enferm. 2016;34(1):69-78.

18. Garzon N. ethical guidelines for research in nursing faculty of the National University of Colombia. Bogota: Research and Extension Center. Ethics Committee; 2008. 1-24 p.

19. Guzman MP. Perception of nursing care in prenatal care services. Montería 2013. Bogota: School of Nursing, National University of Colombia; 2013.

20. Ortega MA. Evaluation of nursing care for women in childbirth process after an intervention. 2017. Bogota: School of Nursing, National University of Colombia; 2017.

21. Suarez DFM, Bejarano MP. Perception of nursing care of pregnant maternity parenting course. Nursing: Humanized care. 2015;4(2):33-39.

22. Maron LC, Beherengaray F, Pachecho IC, et al. Repercussions motives and gives participation of pregnant em prenatal not operating group. Rev Enferm UFSM. 2014;4(3):519-528.

23. Guerreiro E, D Paiva, Azevedo AB, et al. Puerperal health educationgravid no cycle: meanings attributed by postpartum women. Rev Bras Enferm. 2014;67(1):13-21.

24. JD González, Baquero A, Sánchez M, et al. satisfaction of pregnant and accompanying regarding Maternal Education Program in Primary Care. Midwives Rev Prof. 2017;18(1):35-42.

25. Koushede V, Brixval CS, Thygesen LC, et al. Antenatal small-class education versus auditoriumbased lectures to Promote positive transitioning to parenthood - A randomized trial. Rev PloS One. 2017;12(5):e0176819. 